\title{
"...para quién tenga ojos para ver". Martín Noel, el urbanismo de un connaisseur
}

"... for those who have eyes to see." Martín Noel, urbanism from a connoisseur

DOI: https://doi.org/10.18861/ania.2020.10.2.2984
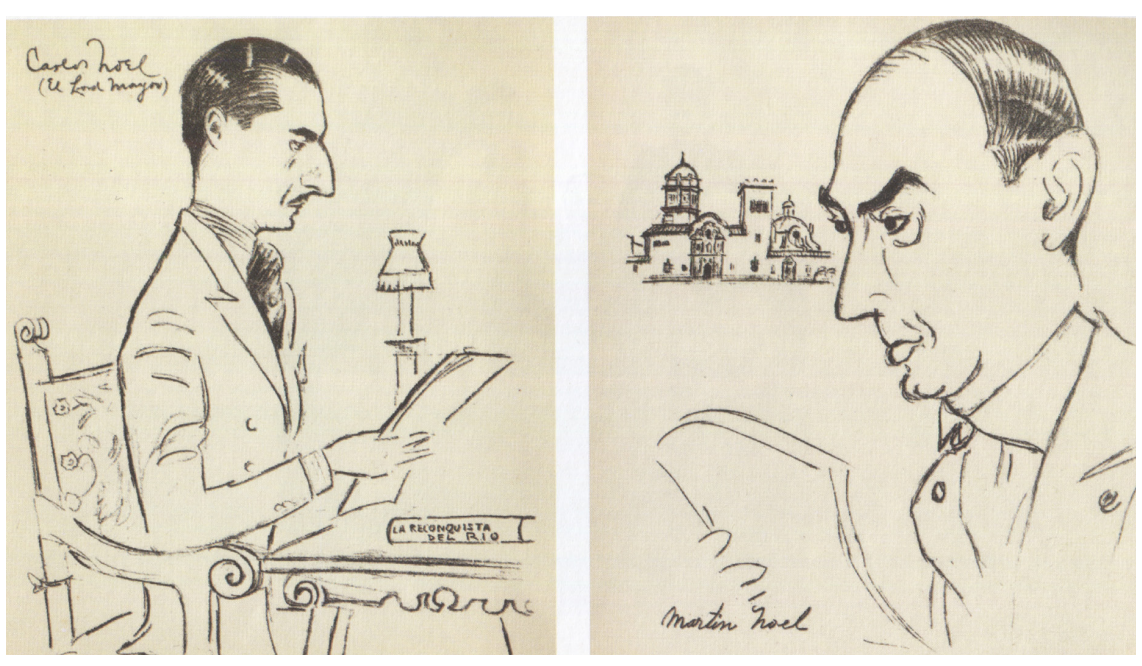
europeas, pero adjudicado al rol nutritivo de los viajes, usa a Spengler y Ruskin. A esta noción de fusión recurre, (CEE), redactora del Proyecto Orgánico de 1925, para

Rigotti, A. M. (2020). Para quién tenga ojos para ver. Martín Noel, el urbanismo de un connaisseur. Anales de Investigación en Arquitectura, 10(2), 7-26. https://doi.org/10.18861/ ania.2020.10.2.2984
Resumen

Pocos ejemplos en Latinoamérica de un connaisseur como Martín Noel. Con un gusto formado en aulas la vista y un lenguaje sustentando en la descripción y los adjetivos para emitir juicios estéticos, adjudicar filiaciones y, aún, laudar sobre esencias culturales impresas en fisonomías que se discierne, sobre todo, en las ciudades como paisaje. El artículo hace énfasis en el viaje como experiencia y sustrato metodológico del Noel historiador, y rastrea la matriz de su aporte teórico -la noción de fusión como germen de un arte colonial autónomo- en fuentes, estrategias expositivas, argumentos y referencias ya como miembro de la Comisión de Estética Edilicia fundamentar, en nombre de la fisonomía esencial de Buenos Aires, la posible conciliación de su condición de ciudad capital con un presente inquietantemente cosmopolita.

\section{Abstract}

In the 1950s a series of Uruguayan architects were based in Ecuador; many of them widely recognized and documented in the local environment. Ethel Arias, Uruguayan architect born in 1925, was part of a privileged group of professionals, national and foreign, who executed emblematic buildings at that time. However, little has been documented of this professional who was the first woman to practice architecture in Ecuador. The study involves brief biographical aspects, the contextualization of the 1950s, a review of the complexities of being a woman in a conservative environment with a masculinized profession, and her learning in Ecuador between the colonial and the indigenous. Finally, his most relevant work, the reconstruction of the Government Palace, is analyzed as part of a discourse on modernity in Quito, with an emphasis on technical decisions as shapers of space, which maintains its characteristics despite several subsequent interventions.

Palabras clave: Urbanismo, arte hispanoamericano, fisionómica, viaje, historia del arte.
Keywords: Urban planning, Hispanic American art, ohysiognomy, travel, art history. 
Leer edificios y ciudades, no documentos

En su ya clásico trabajo, Ramón Gutiérrez (1992) brinda una rica se2-1970) de ascendente carrera fundador del Instituto de Arte Americano e Investigaciones Estéticas (IAA) de Areientemente creada Facultad de Arquitectura en la recientemente creada Facultad de Arquitectura (1888-1963) quién, tras haber dominado las instituciones artísticas (presidente de la Comisión Nacional de Bellas artes entre 1919 y 1930 vicepresidente y presidente de la Academia de Bellas Artes entre 1938 y 1948), declinaba en la suya. Esta confrontación entre dos arquitectos estudiosos, que alcanzó una virulencia pocas veces vista en la profesión, pone en evidencia la singular concepción que Noel tenía de la práctica historica.

Todo comienza con una ácida crítica, en el primer número de los Anales del IAA (1948), a uno de los Cuadernos de Arte Argentino que publicaba la Academia, en realidad poco más que colecciones fotográficas sobre un monumento precedidas por un prólogo. Refrendando estos comentarios, Buschiazzo muestra su indignación frente a datos erróneos y un lenguaje pleno de adjetivaciones hiperbólicas y terminología de dudosa precisión. Según sus palabras, había pasado el momento de libros escritos "poniéndole salsa a unos cuantos grabados" o de vagas disertaciones en torno a teorías del arte mal leídas. Era hora "de ir a los archivos, investigar, documentarse [...] o por lo menos visitar el edificio a cerca del cual se ha de escribir" para ejercitar una crítica severa que "pusiera las cosas en su lugar" en una disciplina que debía avanzar sobre trabajos previos, siempre y cuando "fuera fruto de una labor seria" (Buschiazzo, 1948).
Para alguien como Martín Noel, "a quién nadie osaba Penfrentar" (Adagio, 1996:14) y cuya legitimidad se centraba en cierto "controlinstitucional" por su perten sencia a laba económica y política como miembro de la Unión Cívica Radical se trataba de una afrenta. Su estrategia de defensa desnuda todo un estilo, y una filosofía del arte y la historia No sólo recurre al reconocimiento social (beneplácito del público que asiste a las lecturas de la Academia crónicas en el diario La Nación) como prueba de idoneidad. Plantea límites respecto al valor de las fuentes documentales que dejan fuera "todo ese otro mundo maravilloso de las fuentes integrales del conocimiento y del humanismo, que exige integrales del conocimiento y del humanismo, que exige medio de expresión" (Noel, 1948). Es la diatriba propia de un connaisseur. La aptitud para el juicio estético no se aprende en las aulas, ni se lee en documentos irremediablemente contextuales a la singularidad de la obra y su apreciación. No pretende ganar adeptos.

Se enorgullece de ser parte de una elite tempranamente inmersa en una cultura "de buena casta" y con una autoridad sostenida por el contacto directo con los objetos. En la respuesta de Noel está implícita la distinción de Oswald Spengler (1923: 147) entre la física -que construye imágenes mecánico-causales sobre la naturaleza, subordina el producirse al producto y persigue un conocimiento atemporal, científico, donde prima el concepto de verdadero o falso traducido en leyes y números-, y el pensamiento histórico -propio del mundo de las significaciones, que subordina el producto a un producirse, lleva consigo notas de dirección e irreversibilidad, y resulta contradictorio tratar cientificamente. El método de la historia sería panorámico antes que analítico y, más allá

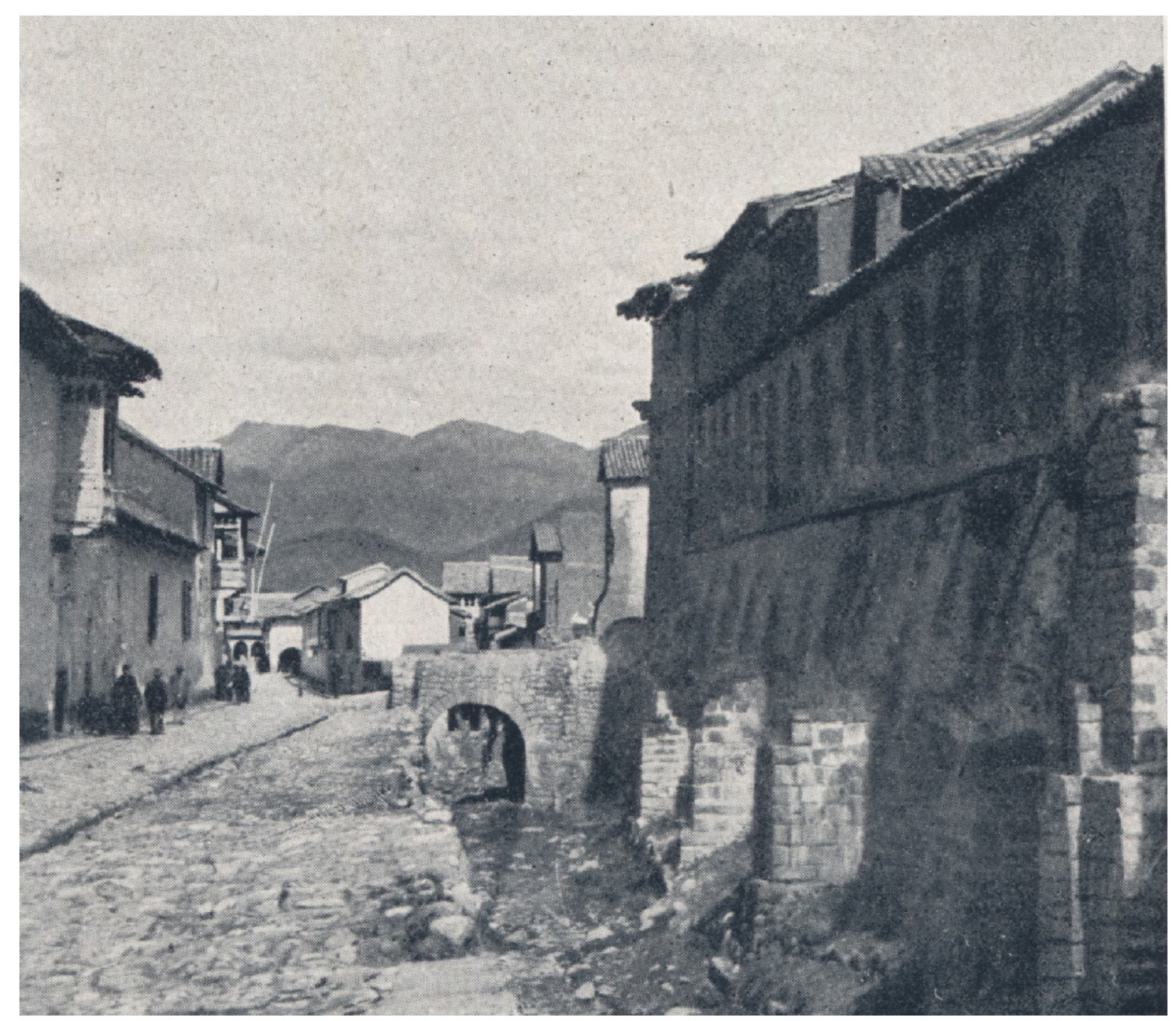

Figura 2: Fotos de viajes e intuiciones: Arequipa. 1919 
del principio de casualidad, capaz de distinguir lo esencial de lo contingente para abordar lo que fue vivo, y fijar su forma y lógica interna (Spengler, 1923: 152-3). El historiador percibiría la encarnación de una cultura en el espacio, en las calles, en la lengua que hablan los edificios, las plazas, los patios, las callejuelas, los rumores, olores y movimientos tanto tiene que tiene que ver con la experiencia, goza te plenitud en raros instantes y se apoya en la intución de plenitud en raros instantes y se apoya en la intuición, "segura como un ensueno" (Spengler, 1923: 163), capaz de sentida. De allí la importancia del viaje que impresiones y contrastes, que se ejercita en la captura de lo fugaz y permite distinguir lo particular arraigado al sitio con un vínculo indestructible y revelador.

Martín, el connaisseur

La figura del connaisseur fue trabajada por Erwin Panofsky. La vincula con el humanista y un saber aportado por ciert infusión de cultura y urbanidad que ninguna universidad puede suplir. Al connaisseur no le interesa el arte desde un punto de vista arqueológico, filológico o crítico, sino como registro de la cultura a la que accede a través de una recreación estética que depende de la sensibilidad natural, el entrenamiento visual y el capital cultural del que aprecia. Lo define como un "historiador del arte lacónico" (Panofsky, 1955:18) que deliberadamente limita su contribución a identificar la proveniencia de una obra y evaluar su calidad, preocupado por la recreación de los procesos antes que por la construcción de una teoría. "Su objetivo es volver a la vida lo que si no permanecería muerto, penetrar en una región donde el tiempo se ha detenido y procurar reactivarlo para capturar le proceso por el cual los vestigios de la cultura fueron producidos y se tornaron en lo que son." (Panofsky, 1955:24)

Se trata de un conocimiento sensual, asociado a la vista como una facultad que puede ser cultivada: no para ver mejor, sino para ver bien y estimular al intelecto para

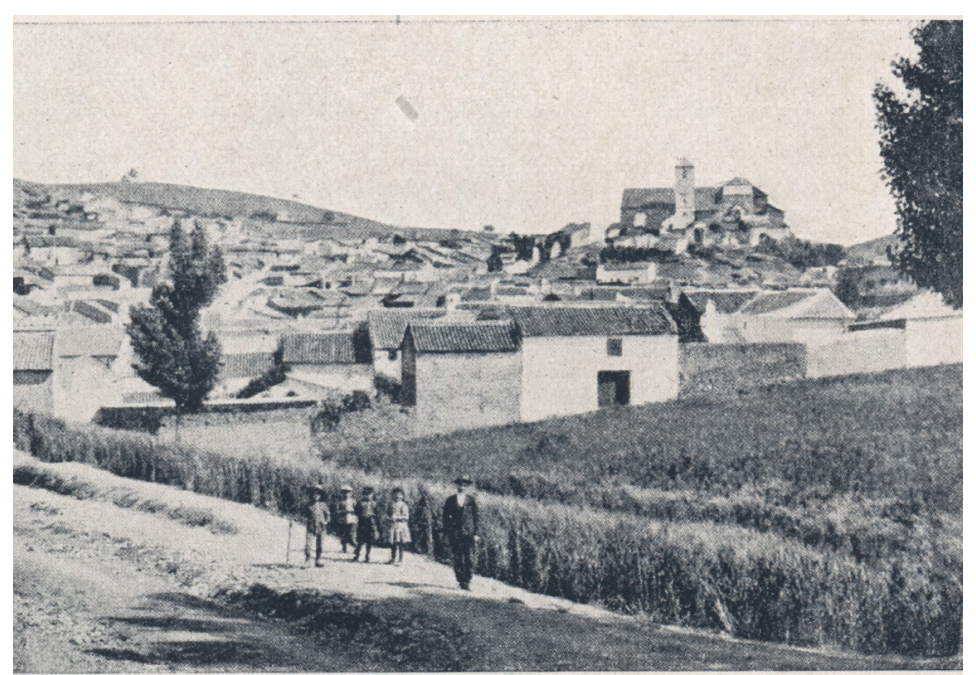

Figura 3: Fotos de viajes e intuiciones: Colmenares ca. 1917.

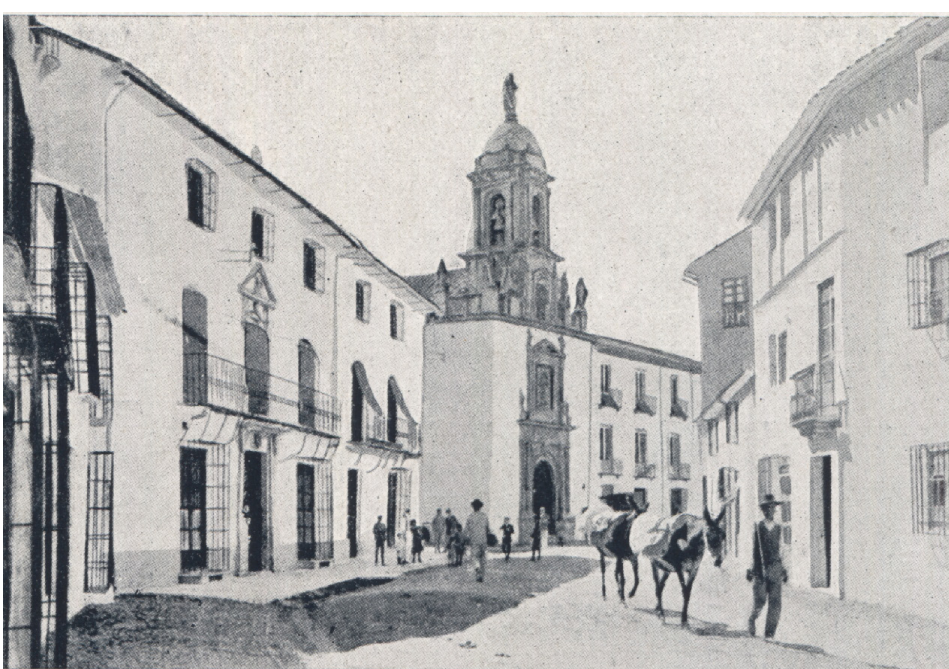

Figura 4: Fotos de viajes e intuiciones: Priego de Córdoba ca. 1917

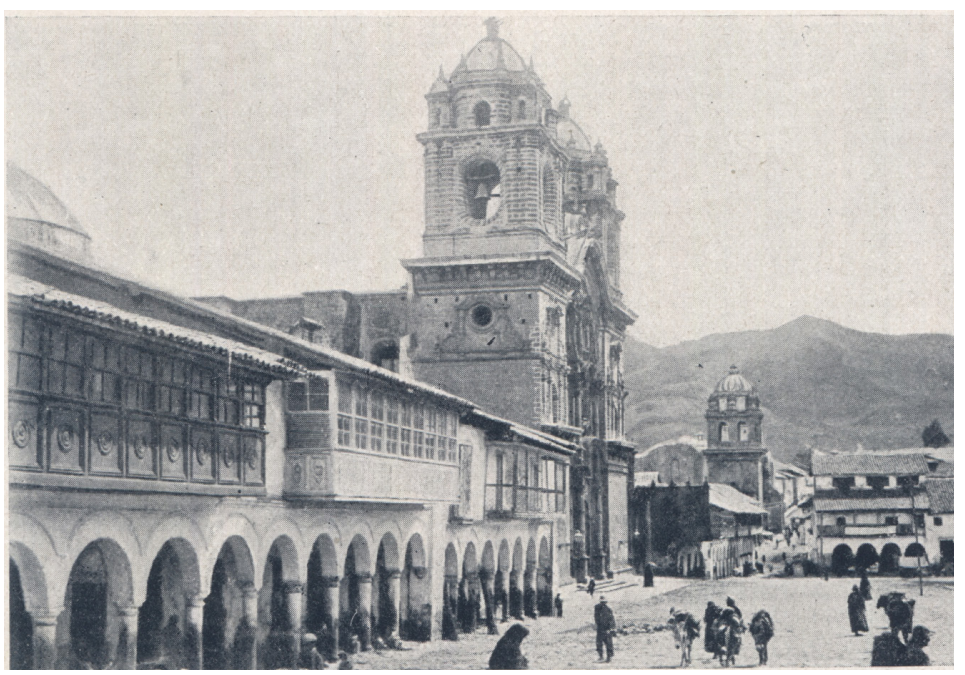

Figura 5: Fotos de viajes e intuiciones: Plaza de Cuzco, 1910 descubrir y hacer observaciones apropiadas (Robinson, 2015:2). Un mirar atento y próximo, que se aleja para apreciar y luego discute sus hallazgos entre gente refinada (Robinson, 2017:7), como la que Noel convoca en sus charlas. Un saber práctico que se educa en la contrastación entre casos diversos, y en la inmersión plena en la producción de una cultura y sus mutaciones en el tiempo. Se trata de un ejercicio de observación cualitativa que solo puede aportar el viaje, abierto a nuevas revelaciones, que sigue una lógica asociativa frente a lo curioso y es capaz de reconocer valor donde nunca antes había sido atribuido. Un saber bien lejano, entonces, a las cartografías académicas.

Martín se ajusta a esta categoría. Como bien lo sugiere los del siglo xVentación, es un gentleman cia económica le permite sumergirse en una práctica que sólo buscado el disfrute visual e intelectual. Se trata del cultivo de las artes, antes que del ejercicio de una profesión. El suyo es el derrotero de un diletante, que también es geográfico, y se asemeja al ejercicio de la virtud como lo testimonia la atmósfera de su estudio en la capilla, de referencias bávaras y coloniales, del palacio que construyera en la calle Suipacha de Buenos Aires. Sólo lo guía la pasión en una suerte de cruzada por la belleza a la que no lo han hecho desistir "ni los alegados eruditos de los menos, ni las aceradas ironías de los más" (Noel, 1930).

No hay dudas del sesgo aristocrático que Noel cultiva en su lenguaje y sus preferencias. Le permite sortear con elegancia su origen de hijo de inmigrante y disponerse como heredero de la prosapia hispánica, al tiempo que muestra condescendencia frente al aporte de "Ios artífices" en la evolución de las artes, y de los inmigrantes en la conformación de una futura Buenos Aires. En su defensa frente a Buschiazzo, acepta gustoso pertenecer a una estirpe en extinción bajo la embestida de las credenciales y las rutinas de los profesionales de la nueva historia, y aún de la arquitectura en su resistencia a las regulaciones en el campo de la construcción (Noel 1933). Su individualismo, su descuidado rechazo a los documentos, son otros sesgos propios del connaisseur: "[...] rechaza la autoridad pero respeta la tradición. No sólo la respeta, sino que la admira como algo real y objetivo que debe ser estudiado y, si fuera necesario, restaurado."(Panofsky 1955:4).

Noel se atribuye la capacidad de saber mirar y juzgar. Expresa sus veredictos mediante adjetivos que procuran sintetizar matices observados y que entiende "indispensables para exaltar el valor sugestivo de los asuntos" (Noel, 1926: 99). Se despega, así, de las referencias 
al material erudito propias de los nuevos historiadores de arte, que escriben mucho pero ven poco. Su aporte es cas instintivo y asociable al degustar experiencias íntimas de primera mano. Argumenta en términos autobiográficos siguiendo la estructura de un diario de viajes; atribuye filiaciones y maridajes nunca sospechados; mide "capacidades germinativas" como las reclamadas por John Ruskin en su apología del gótico (1960:167).

El viaje como experiencia y el viaje como método

Su niñez en Buenos Aires, su viaje nupcial a la Vascongada a visitar familiares, su adolescencia y juventud en Paris, construyen un cosmopolitismo que instruye su capacidad de discernir "fisonomías esenciales" en Europa, el norte de África y las distintas regiones sudamericanas. En las entrevistas y conferencias, gusta presentarse como las entrevistas y conferencias, gusta presentarse como recien llegado a su patria, en estado de shock por las transformaciones durante su ausencia. En, y desde, estos a través de una serie de intuiciones que oscuramente comenzaron en su niñez.

Fue de mí que un día infantil y lejano, descubrí en mis ojos húmedos de ideal y de gozo la poesía agreste y soñadora de la montaña vascongada. Vivía por entonces en San Sebastián y a diario se repetían las excursiones las que, por veces, transformaban se en verdaderos viajes animados de sobresaltos y pintorescas curiosidades. Mas algunas de ellas al saciarse dejaban algo así como un recuerdo hondo y penetrante; y estos recuerdos me atrevo hoy a llamar las revelaciones por cuanto a su trasluz, en el andar monótono de tiempo, fui descubriendo inconscientemente el alma de mis antepasados. Vuelve siempre a la memoria de mi retina de once años el pequeño santuario de Lezo [...] despertando al propio tiempo en mí, por no sé qué extraña coincidencia, la visión de aquellos sábados de gloria de San Telmo. (Noel, 1926:12)
Se trata de revelaciones que, ya liberado de su formación 列 del viaje el método y la posibilidad de conocimiento.

Cuando hube consumado mis estudios de arquitecto en la escuela de París [...] sentí confundida $m$ a trasponer el contrafuerte pirenaico, comencé a a trasponer el cón discernir que era más bien en la tierra andaluza donde habiase her extidos venidos a la penínsultavagante maridaje, los esulos verfostamente definido que casualmente aquel emigrado hasta nosotros. torturado por la idea de una renacimiento hispanotorturado por la idea de una renacimiento hispanonuevas y cavilosas confusiones al enredarme, quizás nuevas y cavilosas confusiones al enredarme, quizás
imprudentemente, en una expedición arqueológica imprudentemente, en una expedición arqueologica fueron se dibujando ante mis ojos, dilatados por fueron se dibujando ante mis ojos, dilatados por tanta e insaciable curiosidad, ciudades, monasterios y
villorrios que a la par que flagelaban las nostalgias del pasado, revestían a todo cuanto miraba con un ropaje característico. (Noel, 1926:14)

La suya es una suerte de deriva. Es la experiencia de formas en movimiento que viran, se trasladan y mutan mientras é avanza, se detiene, reacciona y emprende otros caminos persiguiendo corrientes culturales colectivas en el tiempo y el espacio. $Y$ en ese andar lo asaltan imágenes y certezas que lo acosan hasta dar forma a su teoría de la fusión: no sólo refiere a confluencias, sino a síntesis entre las artes clásicas en estado de peligrosa cosificación y el aporte vivificante de los "artífices", en una clara adopción de las teorías de Ruskin sobre el gótico que leía con esmero.
El desarrollo de los temas de lo llamado clásico en el sentido literal de esta clasificación normalista, termina por ser un simple mecanismo intelectual de la expresión inerte y por el contrario las artes populares vinculadas al origen substancial de su carácter originario constituyen la fuente, la enjundia vital de los organismos estéticos más robustos. (Noel, 1926:3)

Estas experienciasse traducen en un discurso impresionista, bosquejando ideas al correr de la pluma. Más que como historiador, se presenta como un artista transido por una suerte de vocación que lo autoriza a la disculpa antes que caer en las restricciones del método.

\section{No atribuyo a estos escritos un valor complejo de minuciosa}

investigación. Presídelo un afán, un espíritu de artística enseñanza que escapa a la erudición pura; pretende más bien, al amparo de la filosofía, desentrañar de los documentos, de las históricas evocaciones [...] aquella lección viviente, emocional y perdurable que comunica a los seres y a las cosas de esta tierra un algo de eternal bajo la inmensa bóveda celeste.

(Noel, 1923: xi) 
Su imprecisión no es una estrategia para estimular evocaciones pasatistas. Es un método que encuentra en el golpe de vista, en el insight penetrante, la hipótesis arriesgada. Su derrotero lo pone en contacto con ciudades y a quitecturas que, para él, son fuente antes que objeto de estudio. Revelan culturas forjada en el tiempo, cuyos desarrollos y mestizajes imbricados en topografías, climas y luminosidades especialisimas rastrea en el espacio. Y este proceso, operado por artesanos anonimos "en secreta a mistica armonia" con la naturaleza, aunque "mana claro Recurre a la noción de fisonomía también tomada de Recurre a la nocion de fisonomia, tambien tomada de Spengler (1923:103), como forma expresiva y visible de vislumbrar, en las formas, las actitudes y sentidos de un pueblo.

Además de la experiencia directa, otras fuentes privilegiadas son los relatos, dibujos y fotos de viajeros, producto de es misma mirada sorprendida, curiosa, educada en otras geografías, capaz de dilucidar lo singular y característico, lo invisible a los locales por su naturalidad.

Emeric Essex Vidal, que viaja a Buenos Aires desde Montevideo en un barco de guerra, sorprende en trasparentes acuarelas a nuestra ciudad desde el muelle de piedra que mira hacia el fuerte hosco y marcial. Merced a sus pinceles transitamos por la frondosa y romántica alameda, el sitio más agradable de la Villa por su pintoresca belleza y la frescura de aire. (Noel, 1941: 95)

Y la vista fugaz de un paisaje no es sólo fuente, sino inspiración para la idea. Como dice retomando palabras de Kinsley Porter, "por el analisis vivo de las fuentes históricas saboreamos la emoción estética de ta suerte que el deleite pasivo se convierte en actividad creadora" (Noel 1931:28).
El viaje como contexto de descubrimiento se duplica en la demostración. Sus escritos siguen el hilo de lo que va reconociendo y ganan sentido en el desplazamiento. har hablan de trasplantes, hermanamientos, comuniones por empatía reproducir en ellos "motivantes intuiciones que impulsen a la creación".

Andando de viaje, nada hay más obsedante, en materia emotiva que ciertas ciudades que se nos presentan como signos evocadores o descriptivos de sociedades desvanecidas. Venecia, Siena o Pisa en Italia; Toledo, Ávila o Granada en España; alquna ciudades africanas; el viejo Rouen o Saint-Malo en Francia y, por fin, yendo hacia e norte, Brujas en Flandes y Berna en Suiza (...) consiguen despertar ante nuestros ojos la imagen persuasiva de la tesis que tratamos de esbozar. (Noel 1926:236)

Y las adjetivaciones, por momentos abrumadoras, son un instrumento para la que no encuentra sustituto: el arma "para despertar lo sugestivo" y traducir el sabor de una emoción estética que las etiquetas taxonómicas no permite capturar. La fotografía, siempre propia y original, cumple un rol semejante. No son fotos de estudio, ni planos limpios para dilucidar proporciones o detenerse en detalles. Elige encuadres generales, desde el camino, para reproducir aquella perspectiva que capturó su interés y de la que actúa como recordatorio, procurando conservar el vínculo entre la arquitectura y el paisaje próximo.

Derivas en un plan para buenos aires

Martín Noel tuvo un rol relevante en el Proyecto orgánico para la urbanización del Municipio. El Plano Regulador y de Reforma de la Capital Federal como miembro de la Comisión de Estética Edilicia (CEE) que lo redactó, constituida ad hoc por su hermano, Carlos Noel, Intendente Municipal de la ciudad de Buenos Aires. Les había atribuido la tarea de "analizar el vasto problema"
INTENDENCIA MUNICIPAL

COMISIÓN DE ESTĖTICA EDILICIA

\section{PROYECTO ORGÁNICO PARA LA} URBANIZACIỎN DEL MUNICIPIO

EL PLANO REGULADOR Y DE REFORMA DE LA CAPITAL FEDERAL

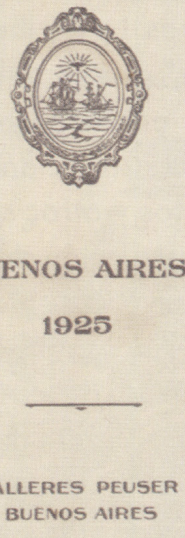

MLERES PEUSER
BUENOS AIRES 
de adecuación de la ciudad a las nuevas demandas sociales $y$ funcionales propias de un explosivo crecimiento signado por la industrialización el "colectivismo" y tráfico automotor y reformarla al tipo de las otras grandes urbes entre las cuales se pretendía ponerla en un pie de igualdad En particular la Comisión debía justificar coordinar prioridades para un vasto programa edilicio realizar con un empréstito de 170 millones de pesos para ro que el Intendente solicita autorización al comienzo de su gestión en diciembre de 1922 Otra tarea subrepticia era establecer en el territorio un tablero que consolidara la alianza política del intendente con las Comisiones de Fomento de los distintos barrios, a fin de contrarrestar un Concejo Deliberante adverso. La resolución se encuentra en una propuesta para descentralizar la gestión en Centros Municipales consolidando la debil identidad de los barrios.

El "Plan Noel", como es comúnmente conocido, resulta relevante como instrumento técnico. Es el primero que adscribe al urbanismo científico y se justifica en un memoria de más de cuatrocientas páginas; es redactado por técnico locales y opera sobre la totalidad de la ciudad para imaginar una metrópoli heterogénea capaz de reunir la Capital con los distintos barrios a través de un nuevo sistema de espacios públicos para la representación de Estado (centros monumentales) y el ocio de las masas (sistema de parques).

Carente de antecedentes urbanísticos, la presencia de Martín Noel en tanto presidente de la Comisión Nacional de Bellas Artes, se justifica por el criterio elegido para constituir la Comisión con representantes de las instituciones vinculadas a los edificios y monumentos públicos de la Nación y el Municipio. En la redacción del plan actúa más como colaborador del proyecto social y político de su hermano, que como reconocido representante de movimiento neocolonial en arquitectura (Gutierrez et alt., 1995). La ciudad tenía que responder a las demandas de inclusión de los sectores populares, en gran parte de origen extranjero. Debía dejar atras su identificación

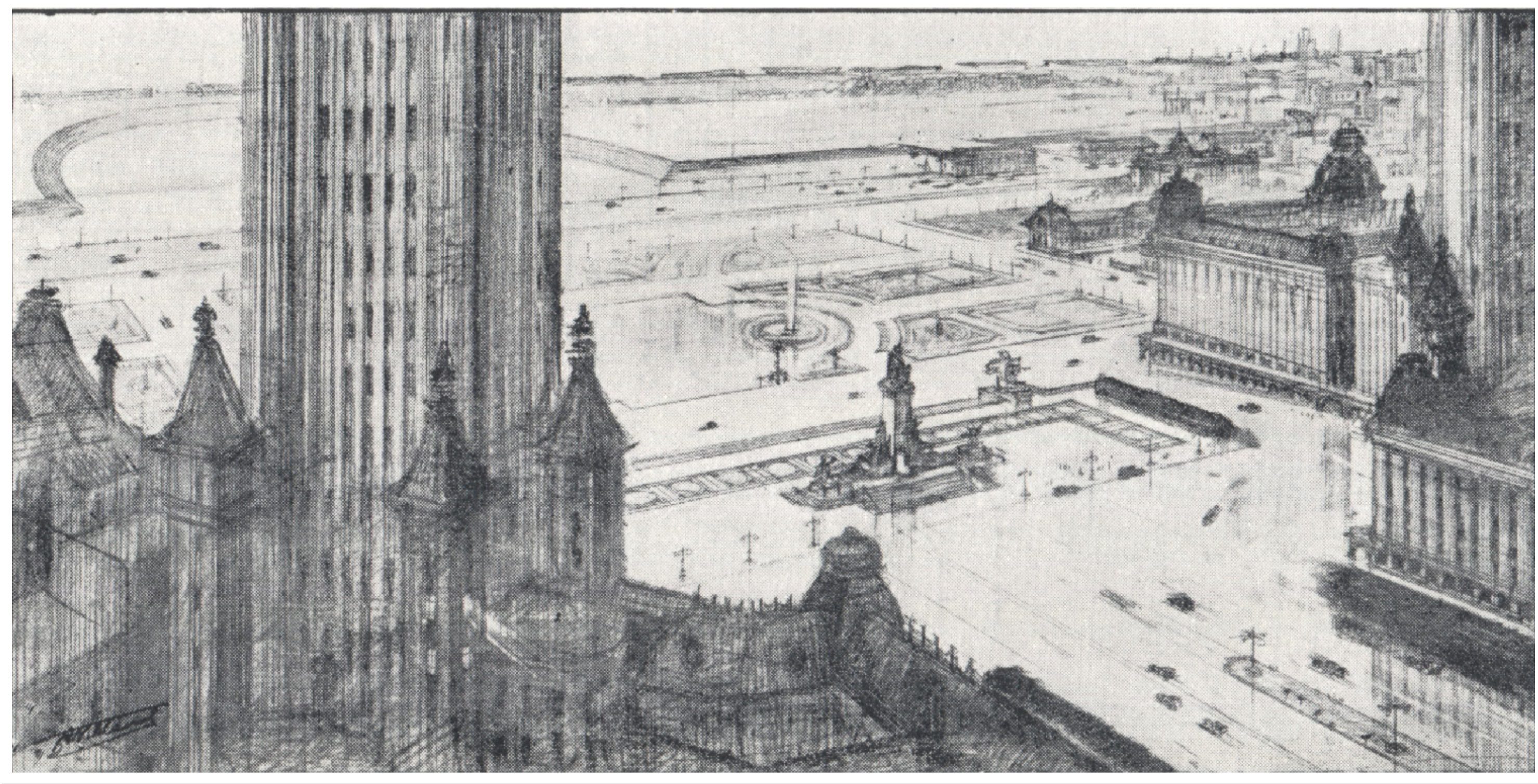

Figura 6: Perspectiva de una prueba de estilo para el proyecto de la Plaza de Mayo, 1925 
con un pasado patriarcal, seguro y mítico, para afrontar la diversidad metropolitana propia de un "desarrollo precipitado e imprevisto".

El protagonismo de Martín Noel se centra en los dos capítulos iniciales. En "El concepto del partido adoptado" urbanismo científico a las particularidades de Bustualistas de Aires, y conjug un actualizado reconocimiento las producciones internacionales donde se destaca recientemente publicado libro de Hegemann \& Peets, The American Vitruvius (Rigotti, 2014:209-210). En la "Breve síntesis histórica" aplica su competencia historiográfica para conciliar la apuesta a una transformación radica con ciertos "valores étnicos" impresos en la "fisonomí con ciertos "valores etnicos" impresos en la "fisonomía fundamental su experiencia como viajero y el testimonio de otros viajeros anteriores.

¿Cómo decretar la muerte definitiva de la Gran Aldea, añorada por una elite que despreciaba y temía la presencia de inmigrantes que, en su ascenso económico, modelaban el paisaje urbano (Cantilo, 1915)? La referencia a una fisonomía, rastreable en los planos y las vistas de la Buenos Aires del siglo XVIII y XIX, resulta providencial. No alude a rasgos definidos, sino a esencias consolidadas en los usos y en los sitios, nutridas por un paisaje característico que pueden guiar y germinar en acciones futuras. Así, la "Breve síntesis histórica" opera como el fundamento de un plan urbano que no se detiene en problemas a resolver, sino en la identificación de ámbitos añorados capaces de regenerar una Buenos Aires que, siendo esencialmente la misma, renazca en clave moderna y cosmopolita.

Este breve ensayo narrativo en el que -a grandes rasgoshemos tratado de sintetizar el curioso y rapido proceso de su desarrollo [...] nos permitirá fijar los rasgos de su fisonomía particular, y ellos a su vez, ayudados por la moderna ciencia del urbanismo, tan admirablemente desarrollado en estos últimos años por las exigencias de los

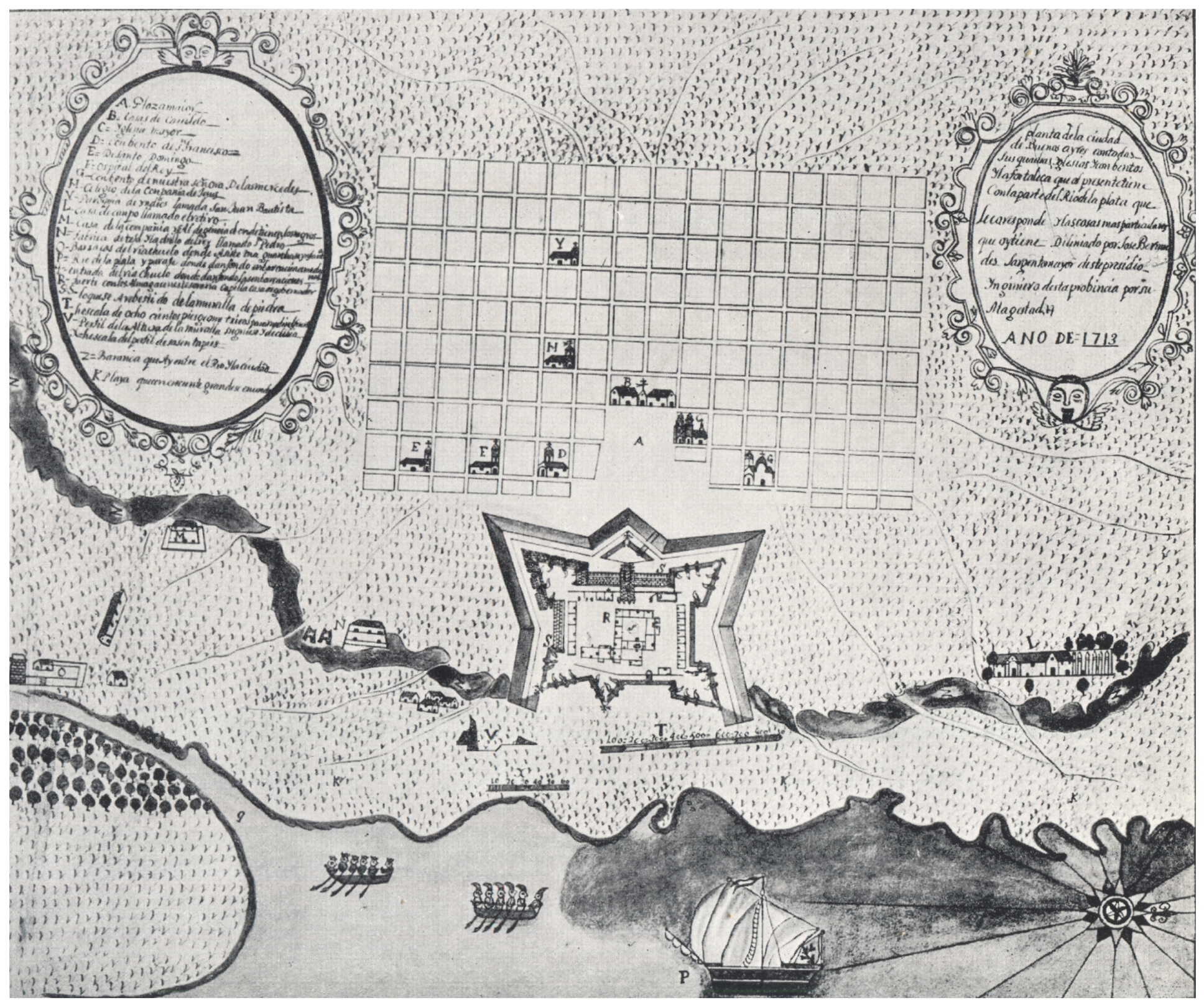

Figura 7: Plano de José Bermúdez de la ciudad de Buenos Aires, 1713. problemas comunes a todas las grandes urbes del mundo, conducirnos hacia las soluciones lógicas encargadas de orientar, en la medida de lo posible, ya en el orden práctico como estético, el futuro desenvolvimiento y progreso a que está destinada nuestra gran metrópoli. (CEE: 52)

Esta crónica de las transformaciones urbanas tiene un ic Uno operativo que identifica esos rasgos doble objetiv. Uno operativo que identifica esos rasgos su evolución Uno doctrinal que reconoce la condición cosmopolita de Buenos Aires y el país todo, al tiempo que enfatiza el dinamismo que esta condición heterogénea de la cultura primordial garantiza a través del concepto de "fusión". Ya hemos señalado cómo Noel, a través de sus escritos sobre historia del arte, demuestra que toda "fusión" resulta estimulante y creativa: entre lo castellano y lo moro, entre lo español y lo incaico, ahora entre la aldea y la metrópoli. La noción se convierte así en garantía para celebrar las diferencias y los intercambios vivificantes entre patricios e inmigrantes, entre lo cívico y el ocio de las masas, entre un pasado superado y un futuro inevitable.

La particular concepción que tiene Noel de la historia, lejos de intereses arqueológicos y objetivos eruditos, le permite definirla como un instrumento de acción. Al identificar en sus edificios y plazas el "numen colectivo e ideológico" de una sociedad, adquiere "un rol fundamental en la transformación imperativa de las ciudades" (Noel, 1927). Así la "Breve síntesis histórica" cumple la función que el urbanismo adjudica al expediente, dossier o survey urbano: una investigación sistemática orientada a subrayar la particularidad del caso, justificar un programa de necesidades específicas $y$, consecuentemente, determinar en forma logica acciones sobre el territorio que superen la abstracción de los trazados de geómetras e ingenieros. En este caso, la secuencia deductiva (mas retorica que real) queda invertida. Enunciado el Programa Edilicio del intendente y difundido por la revista El Arquitecto (Noel C., 1922), se lo justifica a través de la inmanencia de ciertos sitios, ambientes y usos en la evolución urbana de Buenos 


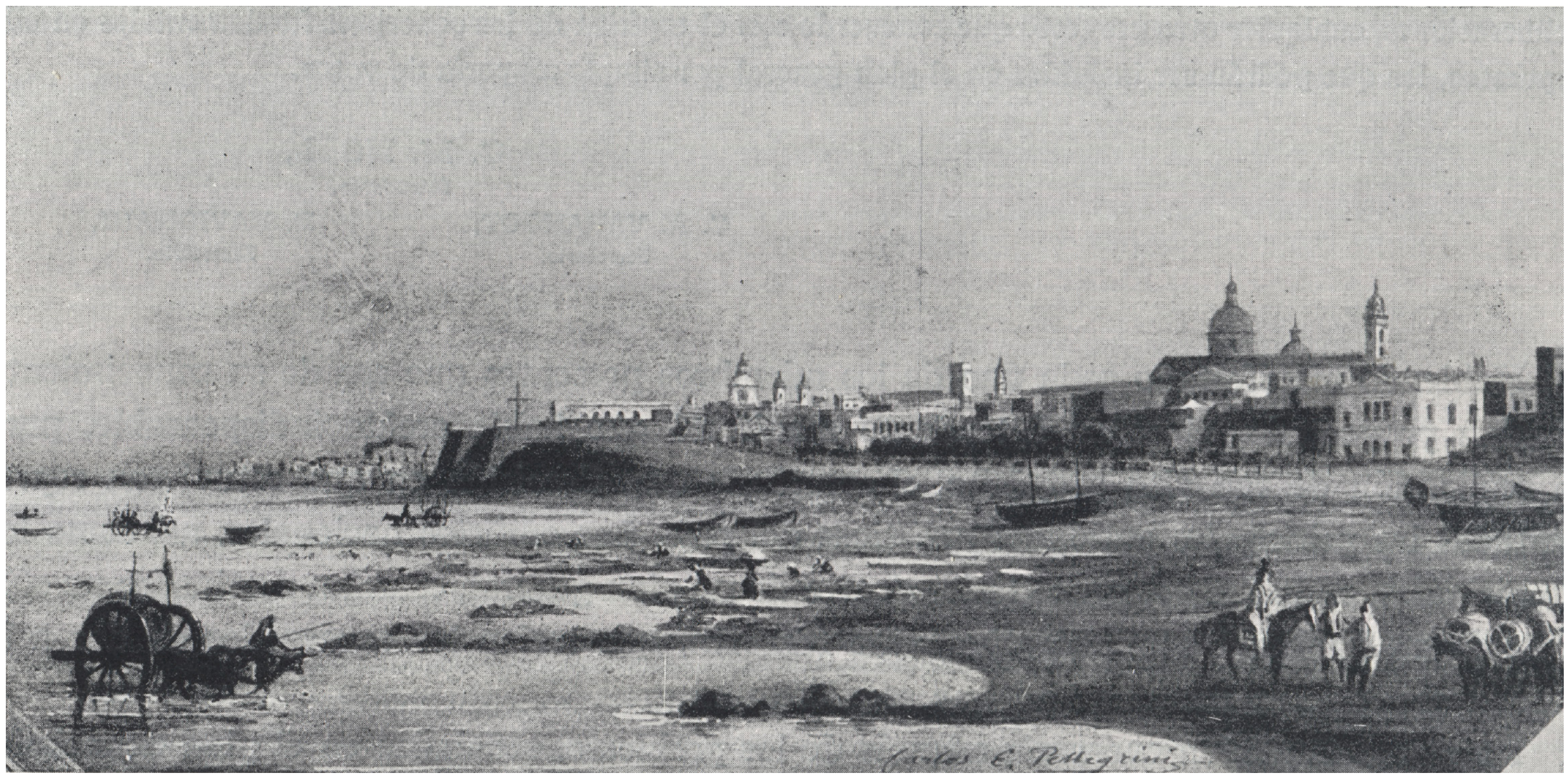

Figura 8: Acuarela de Emeric Essec Vidal sobre la costa de Buenos Aires, 1820
Aires. Los vínculos entre un ayer espontáneo y pleno de potencia, y un futuro auspicioso pero todavía incierto, tienen como propósito subrayar lo que Henri Bergson (1907:23) había definido como la esencia de la vida: la elaboración continua de lo nuevo.

Martín Noel toma el tono de esta corriente vitalista. En lugar de acumular registros tabulados como reflejo de evocar aquellos factores que incidieron en el progreso de la ciudad y especular sobre sus posibilidades para guiar el futuro. Explícitamente procura superar las restricciones del positivismo y capturar el "alma" de una entidad -Buenos Aires- de la que se siente parte. Ninguno de los problemas urbanos modernos podía ser entendido si no se lo trataba en relación a un pasado constructor de identidad Y Yel éxito de su empresa se apoya en el poder de la sugestión. Por eso recurre a la ligereza del trazo evocador propia de los bocetos rápidos de un viajero. Como aconsejaba Raymond Unwin (1909), su indagación no debía ser "ni demasiado extensa, ni demasiado completa" con el propósito de estimular la empatía con el espíritu del lugar, comprometer a la comunidad con sus propias fortalezas, y operar como "fuente concreta de inspiración" para los urbanistas.

Esta historia que construye Noel no solo habla de continuidades, sino de la ruptura definitiva con la Gran Aldea, simbólicamente condensada en la demolición de la Recova bajo la picota de Torcuato de Alvear en 1884, "como si se despojara repentinamente de sus envejecidos ropajes" (CEE: 48). Y la geografía ocupa un lugar fundamental, probablemente debido a la pobreza relativa de la arquitectura porteña. En "la vastedad horizontal y
soñadora de la planicie pampeana" y "la infinita placidez
del río", que sólo un viajero ahíto de tanto paisaje foráneo del río", que sólo un viajero ahíto de tanto paisaje foráneo puede apreciar, encuentra aquella "enérgica plasticidad visual" que determinara el carácter de Buenos Aires. Elige como primera planimetría un curioso mapa topográfico que exacerba las pobres irregularidades del sitio (CEE,
1925:58) para explicar la dispersión de los barrios, el 
despliegue de paseos sobre una costa baja y lodosa, y la posibilidad de vistas hacia el horizonte infinito sobre el valu a hacia el horizonte in inito sobre el los corazones civicos. Yen esta revalorizacín del paiseje toda su sencillez, resulta inestimable la contratación de un experto francés, J. C. N. Forestier (1861-1930), como asesor. Para sorpresa de muchos, Forestier critica la artificiesod de los parterres de la jardinerí francesa y propone de los parterres de la jardinera francesa y propone habí hecho de Buenos Aires un asentamiento singur.

Coincidiendo con la mirada circunstancial de extranjeros en tránsito, también Noel aprecia la sencillez del paisaje urbano local y lo justifica como una versión despojada "de inútiles impurezas" de aquellas corrientes artísticas provenientes de los imperios español e incaico (Noel, 1921: 138-9). Destaca la silueta de los cupulines de Santo DomingoySan Francisco, el discreto abolengo de las "casasesquinas" del "barrio tradicional" de San Telmo dignas de ser restauradas para albergar instituciones artísticas museográficas, el carácter de las "plazuelas" sobre la calle Defensa y los "evocadores" jardines del Parque Lezama. EI embrujo de este paisaje rezagado en el Barrio Sur resulta óptima para resguardar el orden elevado de la educación -artística, filosófica- de los impulsos maquínicos a los que se dispone entregar el resto de Bueno Aires.

Una última consideración merecen las fuentes elegidas Además del conocimiento directo azarosamente jerarquizado por sus recuerdos infantiles, Noel privilegia las imágenes y relatos de viajeros. Reserva la primera ilustración para el ombú, como punto de contraste desde el Camino de las Carretas, para apreciar la masa compacta de las construcciones sobre la barranca del aguafuerte de Fernando Brambilla. Las imágenes elegidas no se detienen en la trama apretada del centro y no hay dudas de la atracción que le provoca el espectáculo del suburbio en las acuarelas de Emeric Vidal. Destaca las vistas amplisimas sobre el estuario del Plata donde se vuelca,

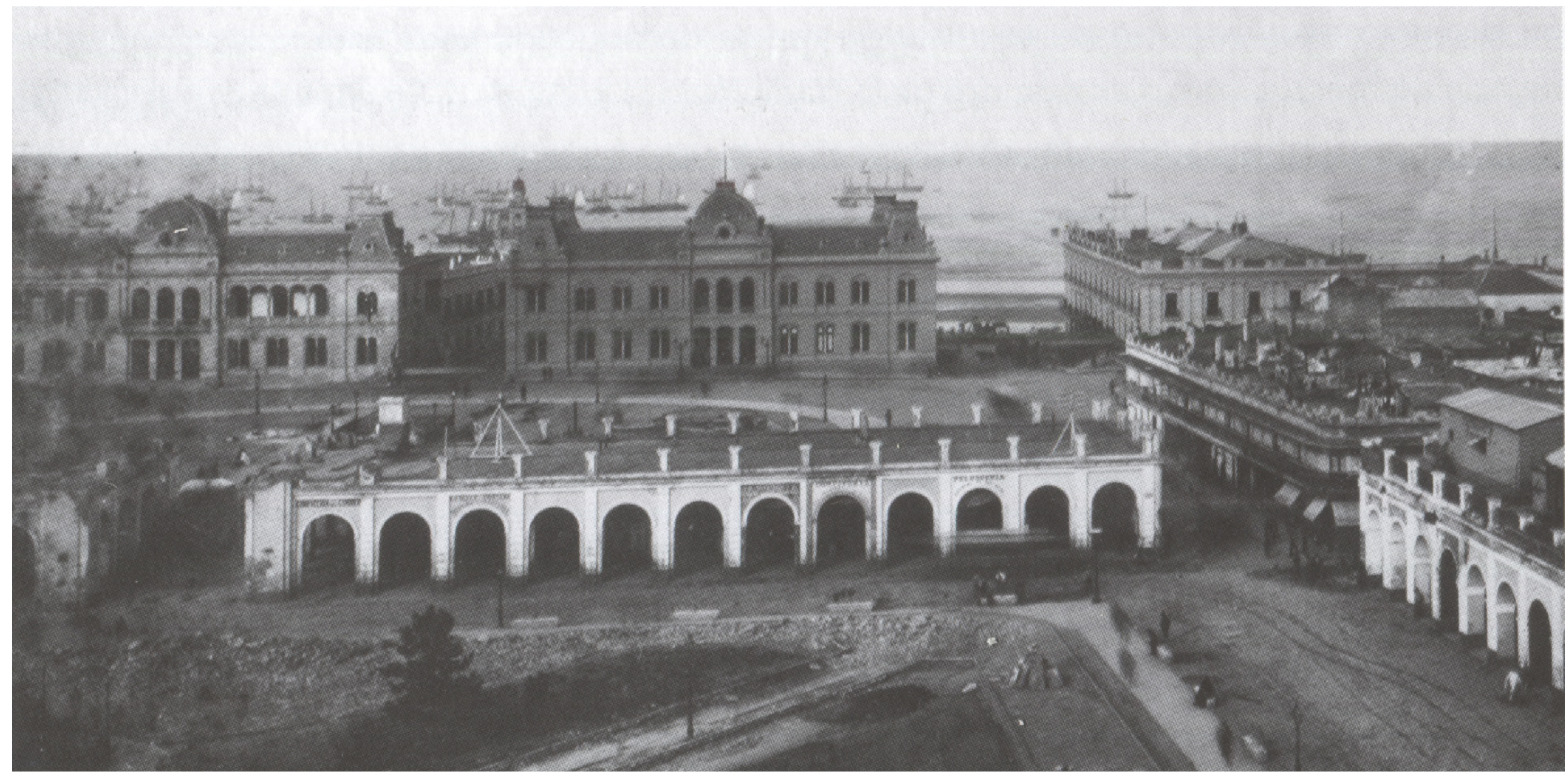

Figura 9: Foto de Alejandro Witcomb de la Plaza de Mayo y la Recova antes de su demolición, 1888. 
sin obstrucciones, la vida institucional y galante de los porteños en plácida armonía con los barcos y el comercio. Prefiere las semblanzas pletoricas de una vida que sólo podía con sover al conocedor cosmín rescata aqu de planos, como el de José Bermúdez en 1713, que togran planos, como el de José Bermúdez en 1713, que logran accidentes, revelando rasgos aún presentes en la forma la ciudad.

En síntesis, Martín Noel, el connaisseur, el viajero, construye una historia que lejos de lidiar con lo muerto y la melancolía, pueda oficiar como instrumento de creación: no un fruto sino una semilla segun las palabras de Bergson. Y la concuentra en esa fisonomía que sólo resulta apreciable en impresa en los primeros asentamientos a la vera del Rio de la Plata, encargada de sintetizar la personalidad de una Argentina joven conmovida por la modernización económica y los flujos de la inmigración, sobre la que el urbanista debe trabajar más como intérnrete de la voluntad colectiva que como creador. Y en esta escucha, a él, al historiador, le cabe el rol de descifrar esa energía primitiva en las cenizas, en las huellas de la ciudad; a su hermano como intendente, la responsabilidad de representar las voces del presente. Nota del autor. Una primera versión de este trabajo fue present do como ponencia a las Terceras Jornadas. La que miran, realizada en Rosario el 26 y 27 de agosto de 2019 y organizada por el Laboratorio de Historia Urbasto CURDIUR/ CONICET y el IAA FADU/UBA. Resulta de la investigación que sirvió de soporte académico a la curadurí, a mi cargo de la exhibición Buenos Aires un Faro Cosmopolita en el Museo de Arte Hispanoamericano Isaac Fernández Blanco de la ciudad de Buenos Aires entre mayo 2019 y marzo 2020 y que se sintetiza en su catálogo (Rigotti et alt 2019) si bien sus hipótesis y desarrollos principales son originales y específicos.

* El Comité Editorial de la revista aprobó la publicación de
Figura 1: Biblioteca Nacional de la República Argentina.

Figura 2: Noel, M. (1923) p. 88

Figura 3: Noel, M. (1923) p. 87

Figura 4: Noel, M. (1923) p. 91

Figura 5: Noel, M. (1923) p. 97.

Figura 6: Comisión de Estética Edilicia (1925).

Figura 7: Comisión de Estética Edilicia (1925) p. 283.

Figura 8: Reproducido en Comisión de Estética Edilicia (1925) p. 12.

Figura 9: Reproducido en Comisión de Estética Edilicia (1925) p. 19

Figura 10: Reproducido en Comisión de Estética Edilicia (1925) p. 17

Figura 11: Reproducido en Comisión de Estética Edilicia (1925) p. 30 
ADAGIO, N. (1996). La historia de la arquitectura hispanoamericana. Martín Noel entre 1919 1932. 6tas Jornadas Nacionales Interescuelas y Departamentos de Historia.

BERGSON, H. (1907) L'évolution créatrice, Paris: F. Alcan.

BUSCHIAZZO, M. (1948). Carta a Martín Noel, Adrogué 20 de mayo. Archivo Martín Noel, Galería Zubarán Citada por Gutierrez (1992:11).

CANTILO, J. L. (1915). La obra futura. Revista de Arquitectura 1 (6-7).

COMISIÓN DE ESTÉTICA EDILICIA (1925). Proyecto orgánico para la urbanización del Municipio. El Plano Regulador y de Reforma de la Capital Federal. Buenos Aires: Talleres Peuser.

GUTIÉRREZ, R. (1992). Origen historiográfico de la polémica Noel- Buschiazzo 1948-1950. DANA $31-32(17-14)$

GUTIÉRREZ, R., GUTMAN, M., \& PEREZ ESCOLANO, V. (1995). Martín Noel, su tiempo y su obra. Sevilla: Junta de Andalucía y Universidad de Buenos Aires.

HEGEMANN, W., \& PEETS, E. (1922). The American Vitruvius: An Architects' Handbook of Civic Art. Reprint New York: Princeton Architectural Press, 1988

NOEL, C. (1922). Plan de Acción de la Intendencia. El arquitecto 29 (134-140).

NOEL, M. (1915). Comentarios sobre el nacimiento de la arquitectura hispano-americana. Revista de Arquitectura 1, año 1 (8-12).

NOEL, M. (1921a). El Barroco Andaluz y la Arquitectura de la Colonia. Contribución a la Historia de la Arquitectura Hispano-Americana. Buenos Aires, Talleres S. A. Casa Jacobo Peuser, 1923 (59-139).

NOEL, M. (1921b). La Arquitectura Hispano-Americana en el Cabildo de Luján. Contribución a la Historia de la Arquitectura Hispano-Americana. Buenos Aires, Talleres S. A. Casa Jacobo Peuser Ltda. 1923 (143 155).

NOEL, M. (1923). Contribución a la Historia de la Arquitectura Hispano-Americana. Buenos Aires: Talleres S. A. Casa Jacobo Peuser.

NOEL, M. (1924). El nacionalismo como fuente de personalidad artística. El arquitecto 51 (V) (65-73)
NOEL, M. (1927, 28 octubre). Evolución y carácter de la ciudad. La Prensa.

NOEL, M. (1930). Hablando con don Martín S. Noel. CAYCA 29 (73-75).

NOEL, M. (1931). Racialismo y arquitectura. Revista de Arquitectura 121, año XVII (28-37).

NOEL, M. (1933). Sobre la reglamentación de la profesión de arquitecto. CAYCA 68(4) 205/6.

NOEL, M. (1938, 16 marzo). La demolición de la Casa Rosada. Noticias gráficas.

NOEL, M. (1941). El Buenos Aires de la Independencia. Palabras en acción. Apologías y temas de Historia, Arte y Urbanismo, Buenos Aires: Editorial Peuser, (93-104).

NOEL, M. (1948). Carta a Mario Buschiazzo. Buenos Aires, 29 mayo. Archivo Noel, Galería Zubarán. Citada por Gutierrez (1992:12).

PANOFSKY, E. (1955). Art as a Humanistic Discipline. Meaning in the Visual Arts. Nueva York: Doubleday Anchor Books.

UNWIN, R. (1909). Town Planning in Practice: An Introduction to the Art of Designing Cities and Suburbs, Londres: T. Fisher Unwin.

SPENGLER, O.(1923). La decadencia de occidente, Tomo 1 (traducción Manuel García Morente) Madrid: Espasa Calpe [1918]

RIGOTTI, A. M. (2014) Las invenciones del urbanismo en Argentina 1900-1960. Rosario: UNR editora RIGOTTI, A M., MENÉNDEZ E., \& ALEXANDER, A (2019). Buenos Aires, un faro cosmopolita. El plan Noel 1922/1925. Buenos Aires: Museo Fernández Blanco.

ROBINSON, T. (2017). Eighteenth-Century Connoisseurship and the Female Body. Oxford Handbooks Online DOI: 10.1093/oxfordhb/9780199935338.013.139.

RUSKIN, J. (1960). The Stones of Venice. Nueva York [1853].

VIDAL, E. (1820). Picturesque Illustrations of Buenos Ayres and Montevideo, Londres: M Ackerman. 